Fisheries, 1995, v.20, n.10, pp.14-21

ISSN: $1548-8446$

DOI: 10.1577/1548-8446(1995)020<0014:MIATRP>2.0.CO;2,

http://afs.allenpress.com/perlserv/?request=get-archive\&ct $=1$

http://afs.allenpress.com/archive/1548-8446/20/10/pdf/i1548-8446-20-10-14.pdf (C)American Fisheries Society 1995 


\title{
Management Issues and Their Relative Priority within State Fisheries Agencies
}

\author{
By Martha E. Mather, Donna L. Parrish, Roy A. Stein, and Robert M. Muth
}

\begin{abstract}
For researchers and managers to work together for greatest mutual benefit, researchers must understand what issues fisheries managers consider most important. To assess management priorities, we conducted a mail survey asking U.S. state fisheries agencies to identify the priority, based on personnel time, they place on 12 fisheries management issues. Based on an $88 \%$ response rate, we determined relative emphases across (1) management issues, (2) geographic regions, and (3) freshwater or marine orientations. Issues directly linked to sport and commercial fishers, i.e., stocking, harvest regulations, fishing pressure, and exploring recruitment, were of paramount importance in all agency time budgets. The issue that included conflict, policy, and human dimensions concerns also was identified as "high priority." Six other issueshabitat restoration, hydropower licensing, instream flow, contaminants, introduced species, and nongame species-were of "moderate priority" nationwide. Approximately $50 \%$ of the issues varied in emphases across geographic region, and five issues were differentially emphasized in agencies with freshwater and marine responsibilities. To solve persistent problems that plague fisheries management, agencies must clearly identify high-priority management concerns and communicate their specific problem-solving needs to researchers. Results of this survey should provide a first step in identifying these management priorities and research needs.
\end{abstract}

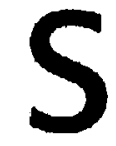

tate fisheries management agencies have specific objectives and constraints when allocating personnel time to resource management. Of course, charges to these agencies vary from state to state and are continually modified. However, for all agencies, a diverse array of user groups coupled with a climate of fiscal austerity makes identifying, prioritizing, and developing effective solutions to resource allocation and management problems critical and difficult. In our view, problem-solving research can help agencies deal with management issues more efficiently and effectively. However, for researchers and managers to work together for greatest mutual benefit, researchers require an understanding of those issues that fisheries managers consider most important (Parrish et al. 1995, this issue).

Many criteria exist with which to evaluate both the relative importance of management concerns and the hierarchy of critical research needs within an agency. To assess management priorities, we conducted a mail survey asking state fisheries management agencies to identify the extent to which they emphasized 12 fisheries management issues using one possible criterion, the allocation of agency personnel time. Although a direct relationship may not exist between allocation of personnel time within an agency and an agency's need for information via research, the prioritization of management concerns based on how an agency allocates staff time provides key information on issues of importance to fisheries managers. With the results of this survey in hand, we then determined if differences in agency time allocation occurred across issues, across geographic regions, and between inland and marine agencies.

Martha E. Mather is assistant unit leader for the Massachusetts Cooperative Fish and Wildlife Research Unit, Department of Forestry and Wildlife Management, Holdsworth Hall, University of Massachusetts, Amherst, MA 01003; 413/545-4895; mather@forwild.umass.edu; Donna L. Parrish is assistant unit leader for the Vermont Cooperative Fish and Wildlife Research Unit, Burlington, VT 05405. Roy A. Stein is a professor of zoology at the Aquatic Ecology Laboratory, Department of Zoology, The Ohio State University, Columbus, $\mathrm{OH}$ 43212. Robert M. Muth is an assistant professor of natural resource policy and administration at the Department of Forestry and Wildlife Management, University of Massachusetts, Amherst, MA 01003. 


\section{Methods}

Participants. We mailed surveys

tive heads of all 66 nonfederal agencies with fisheries management responsibilities in the states, commonwealths, districts, and territories of the United States (hereafter called states; $N=52$ ) listed in the 1991 national and state listing of fisheries offices (USFWS 1991). We asked our agency administrative contact to give the survey to the person who dealt with allocation of agency staff time. Though we acknowledge that including federal fisheries managers and Canadian agency biologists would have been valuable, we chose to focus this survey only on U.S. state agencies. Because some states listed more than one agency, typically freshwater and marine, some states filed multiple responses. We sent 66 surveys on 12 June 1993; on 9 August 1993, we sent a second copy of the survey to nonrespondents. From these mailings, 58 of 66 agencies returned surveys in 46 of 52 states, resulting in response rates of $88 \%$ for both agencies and states (Table 1).

\section{Survey Content. For each of 12} sues, we asked respondents to select one of three possible responses (i.e., "major emphasis," "minor emphasis," or "no emphasis") to discern the level of emphasis, as represented by current allocation of agency personnel time, that their agency placed on each management issue. For each question, these levels of emphases summed to $100 \%$. The management issues were briefly described as follows: (1) sportfish stocking (SPORTFISH); (2) forage stocking (FORAGE); (3) assessment of the effectiveness of harvest regulations (HARVEST);

(4) evaluation of fishing pressure (PRESSURE); (5) exploration of recruitment (RECRUITMENT); (6) hydropower licensing or regulated flow (HYDROPOWER); (7) instream flow (INSTREAM); (8) nongame, threatened, or endangered species

Table 1. Demographics of agencies that responded to an agency time allocation survey conducted in 1993. States, commonwealths, districts, and territories are grouped in the geographic divisions used by the American Fisheries Society. Numbers in parentheses correspond to the number of responses returned compared to the number solicited. As some states are composed of multiple agencies, typically inland and marine, some states respond more than once.

\begin{tabular}{|c|c|c|c|c|c|}
\hline & & Northeasterm & Division & & \\
\hline Conn & (1) 011$)$ & Delaware & & Wame & (2) 012$)$ \\
\hline New York & $(2$ of 2$)$ & Pennsvlyania & & Icland & $(1<$ of 2$)$ \\
\hline Vern & (1 of 1 ) & & & & \\
\hline Northeastern & & State & (10 of 10$)$ & Agency & (14 of 15) \\
\hline & & Southern $\mathrm{c}$ & ivis & & \\
\hline Alabama & (2 of 2) & Arkansas & $(1$ of 1$)$ & Florida & (2 of 2) \\
\hline Georgia & $(2$ of 2$)$ & Kentucky & (1 of 1$)$ & Louisiana & (2 of 2) \\
\hline Maryland & (1 of 1$)$ & Mississippi & $(2$ of 2$)$ & North Carolina & $(2$ of 2$)$ \\
\hline Oklahoma & (1 of 1$)$ & Puerto Rico & $(1$ of 1$)$ & South Carolina & $(1$ of 2$)$ \\
\hline Tennessee & ( 1 of 1 ) & Texas & $(1$ of 1$)$ & Virginia & (2 of 2$)$ \\
\hline Southern & & State & (16 of 17) & Agency & (23 of 24) \\
\hline & & North Centra & I Division & & \\
\hline Illinois & (1 of 1$)$ & lowa & $(1$ of 1$)$ & Kansas & (1 of 1$)$ \\
\hline & (1 of 1$)$ & Minnesota & $(10$ & Missouri & (1 of 1$)$ \\
\hline $\begin{array}{l}\text { Nebraska } \\
\text { North Central }\end{array}$ & $(1$ of 1$)$ & $\begin{array}{l}\text { North Dakota } \\
\text { State }\end{array}$ & $\begin{array}{l}(1 \text { of } 1) \\
(9 \text { of } 12)\end{array}$ & $\begin{array}{l}\text { Ohio } \\
\text { Agency }\end{array}$ & $\begin{array}{l}(1 \text { of } 1) \\
(9 \text { of } 12)\end{array}$ \\
\hline & & Western D & ivision & & \\
\hline Alaska & $(1$ of 1$)$ & Arizona & (1 of 1$)$ & Colorado & ( 1 of 1$)$ \\
\hline Hawaii & (1 of 1$)$ & Idaho & $(1$ of 1$)$ & Montana & (1 of 1$)$ \\
\hline Nevada & ( 1 of 1$)$ & New Mexico & (1 of 1$)$ & Utah & $(1$ of 1$)$ \\
\hline $\begin{array}{l}\text { Washington } \\
\text { Western }\end{array}$ & $(2$ of 2$)$ & $\begin{array}{l}\text { Wyoming } \\
\text { State }\end{array}$ & $\begin{array}{l}(1 \text { of } 1) \\
(11 \text { of } 13)\end{array}$ & Agency & (12 of 15) \\
\hline TOTAL & & STATE & (46 of 52) & AGENCY & (58 of 66) \\
\hline
\end{tabular}

(NONGAME); (9) introduced species (INTRODUCED); (10) contaminants (CONTAMINANTS); (11) habitat restoration (HABITAT); and (12) conflict, policy, or human dimensions issues (CONFLICT). We abbreviate these issues on the figures and tables that follow, but all issues were fully described on the questionnaire to avoid ambiguity. The 12 issues were chosen subjectively by the authors based on a review of papers in current fisheries journals.

\section{Analysis. We processed all} However, when a respondent simultaneously indicated more than one level of emphasis for any single issue, this ambiguous response was omitted from the analysis for that question only. Usually, we had 51-55 responses for each of the 12 questions identifying 12 issues. Because not all participants completed all questions, response number varied across questions. In analyzing all usable responses to each question, we summarized percent "major emphasis," percent "minor emphasis," and percent "no emphasis," although in our discussion we focus primarily on percent "major emphasis."

To assess the relative importance of these 12 primary issues, we performed a series of chi-square tests. First, for each issue, we used a chisquare test to compare percent "major+minor" responses to an expected value of $50 \%(100 \% / 2$ possible responses, i.e., "major + minor" or "no emphasis;" Dowdy and 


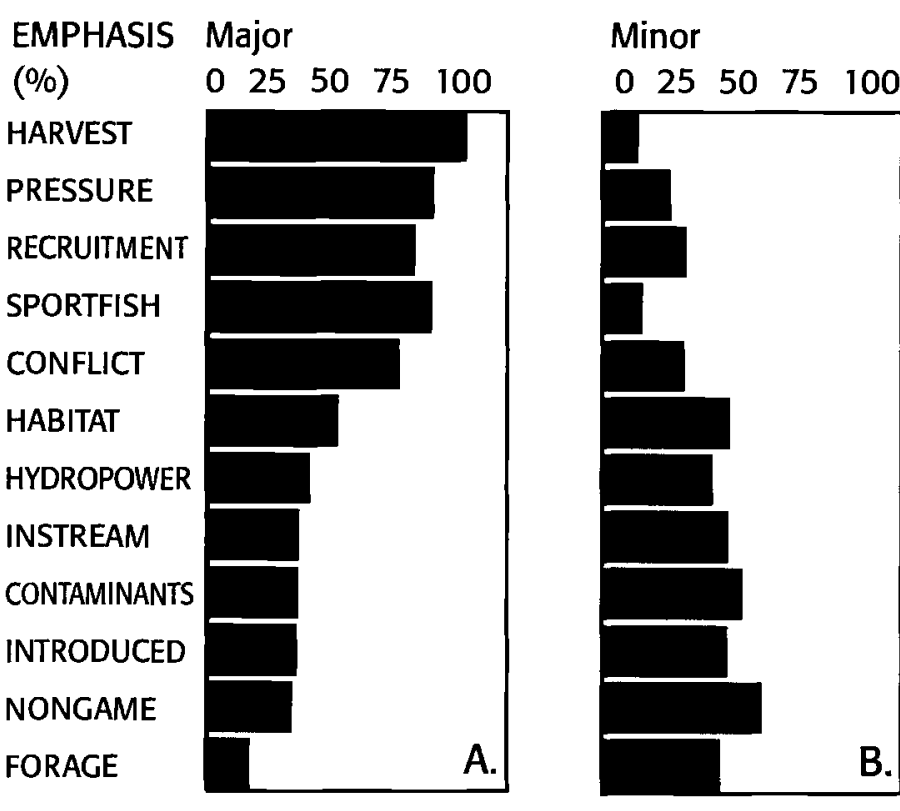

Fig. 1. Percent "major," "minor," and "no emphasis" for 12 fisheries management issues expressed by respondents to a time allocation mail survey administered in 1993. Targeted management issues are abbreviated on the $Y$ axis but were fully described on the survey questionnaire as follows: (1) applying or assessing the effectiveness of harvest regulations (HARVEST); (2) evaluation of fishing pressure (PRESSURE); (3) sportfish stocking (SPORTFISH); (4) recruitment (RECRUITMENT); (5) conflict, policy, and human dimensions issues (CONFLICT); (6) habitat restoration (HABITAT); (7) hydropower licensing or regulated flow (HYDROPOWER); (8) instream flow (INSTREAM); (9) contaminants (CONTAMINANTS); (10) introduced species (INTRODUCED); (11) nongame, threatened, or endangered species (NONGAME); and (12) forage stocking (FORAGE). Panel $A$ depicts the percent of respondents that indicated a "major emphasis" relative to agency staff time allocation for each of these management issues. Panel B shows the percent of respondents that indicated a "minor emphasis" for the same issues, and in Panel $\mathrm{C}$, the percent of respondents that answered "no emphasis" is shown. For each of the 12 issues and questions, percent "major," "minor," and "no emphasis" sum to 100\%. N = 51-55 for each question.
No
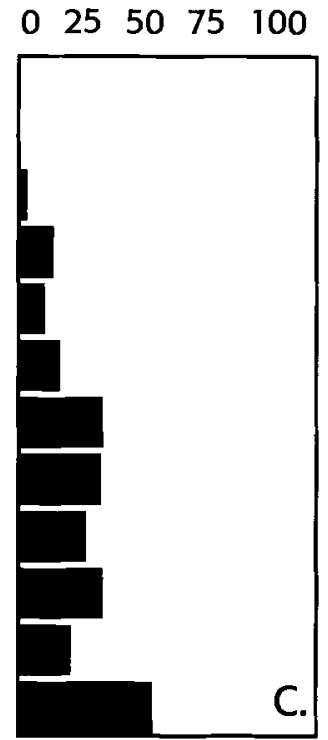

Results and Discussion

\section{Overall Rankings.}

Below, we evaluate the emphases that agencies reported placing on 12 management issues based on allocation of personnel time. Percent "major emphasis" ranged from a high of $88 \%$ (harvest regulations) to a low of $15 \%$ (forage stocking; Fig. 1). In addition, only one issue (forage stocking) received a higher percentage of "no emphasis" responses than combined "major" and "minor emphasis" responses (Fig. 1; Table 2a), suggesting that 11 of these 12 manage-

regions, we assigned responses to one of the four geographic divisions used by the American Fisheries Society (AFS), i.e., Northeastern (NE), Southern (SO), North Central (NC), and Western (WE; Table 1). To test for geographic differences, we compared the observed responses within

Wearden 1991). Second, to determine if for any issue percent "major emphasis" differed from percent "minor emphasis" or percent "no emphasis" based on chance alone, we used a chi-square test to compare the observed percent "major emphasis" to an expected value of $33 \%(100 \% / 3$ possible responses, i.e., "major," "minor," or "no emphasis"). Third, to determine if one issue was of paramount importance in personnel time allocation, we used a chi-square test to compare the observed response for each question to an expected value of $8.3 \%$ (100\%/12 issues) based on what might be expected due to chance alone.

To determine if differences in issue emphases existed across geographic each geographic division to an expected value of $25 \%$ (100\%/4 geographic divisions). Finally, we tested if system orientation influenced response by using a chi-square test to compare observed responses, grouped by freshwater or marine orientation, to an expected value of $50 \%$ (100\%/ 2 orientations). Two states that listed both freshwater (FW) and marine (MA) agencies responded with a single, combinedsystem questionnaire, and four states with ocean access were listed under a single management agency. Hence, for these six respondents, we could not separate marine and freshwater orientations and these questionnaires were omitted from the system orientation analysis $(F W=37 ; \mathrm{MA}=15)$. ment issues were sufficiently important to receive agency attention.

However, when the frequency of percent "major emphasis" for all 12 issues was evaluated relative to an expected percent of $8.3 \%$ (i.e., $100 \% / 12$ issues), some issues received "major emphasis" responses more often than others $\left(X^{2}=69.35, D F=11, P \leq 0.001\right)$, suggesting that agency staff time was not allocated equally among issues. Further, by combining the pattern of percent "major emphasis" (Fig. 1a) with percent "no emphasis" (Fig. 1c), a hierarchy emerged that may help us identify both nationwide and regional management priorities. Based on this hierarchy, we grouped these 12 issues into three priority categories: "high," "moderate," and "low." Percent "minor" emphasis (Fig. 1b) provided little new information and was largely ignored.

In our judgment, five issues deserve to be classified as "high priority" because $65 \%-88 \%$ of the respondents indicated that these issues received major emphasis in terms of staff time allocation (Fig. 1a). Three of these "high priority" issues, i.e., harvest regulations (88\%), fishing pressure $(77 \%)$, and exploring recruitment $(70 \%)$, received "major emphasis" from more than twothirds of respondents (Fig. 1a). In addition, no agencies $(\leq 2 \%)$ indicated that these three issues received "no emphasis" (Fig. 1c). Thus, these 
three issues represent concerns that transcend state and regional boundaries and require staff time from most state fisheries management agencies in the United States. At the same time, two other "high priority" issues, i.e., sportfish stocking $(76 \%)$ and the issue collectively identified as conflict, policy, and human dimensions concerns (65\%), also received "major emphasis" from about two-thirds of the respondents (Fig. 1a). However, a higher percentage of respondents indicated that these two issues received "no emphasis" from their agencies (11\% and $8 \%$ for sportfish stocking and conflict, respectively; Fig. 1c), suggesting that, whereas these issues were important, slight between-state differences exist. All five of these issues received a higher proportion of "major emphasis" responses than we would expect by chance alone (Table $2 \mathrm{~b}$ ).

The "high priority" status of four of these five issues (harvest regulations, fishing pressure, recruitment, and sportfish stocking) reflects the strong extant linkage between state fisheries management agencies and sportfishers or commercial fishers, especially license-buyers. A significant proportion of state agency funding comes from both license sales and excise taxes levied on fishing equipment and motorboat fuel as authorized by the Federal Aid in Sport Fish Restoration Act, i.e., Dingell-Johnson funds as modified by the Wallop-Breaux amendment. Sport Fish Restoration funds specifically are apportioned to state fisheries agencies by the federal government based on fishing license sales and within-state surface water area. Consequently, a built-in constituent for state agencies becomes the fishing public; agencies must then continue to focus strongly on sportfish management. The dominance of the fifth "high-priority" issue (conflict, policy, and human dimensions concerns) suggests that a number of contentious natural resource issues exist across the country. These controversies may be exacerbated by increasing population size, expanding industrialization and urbanization, and increasing differentiation of social values ascribed to fisheries resources. Thus, the presence of conflicting demands among resource users places conflict, policy, and human dimensions concerns in the forefront for most managers.

Six other issues formed a second "moderate-priority" category in which emphases differed greatly across agencies. These issues were habitat restoration; hydropower; instream flow; contaminants; introduced species; and nongame, threatened, and endangered species. These issues received a higher percentage of "majoremphasis" responses (29\%-44\%;

Fig. 1a) than "no-emphasis" responses (13\%-8\%; Fig. 1c) but required less agency time on average than "highpriority" issues. For these issues, either the frequency of percent "major-emphasis" responses did not differ from chance or, if significantly different from $33 \%$, the pattern of inequality favored percent "minor emphasis" rather than percent "majoremphasis" responses (Table $2 \mathrm{~b}$ ). The last issue, forage stocking, formed a third "low-priority" category ("major emphasis," 15\%; "no emphasis," $45 \%$; Fig. 1a, c; Table 2a,b) and was an unimportant activity in the time budget of nearly half of the managers surveyed.

\section{Geographic Trends. Additional}

tion on the emphases given these issues by state agencies was revealed when we examined geographic trends (Fig. 2, 3). Three "high-priority" issues, i.e., harvest regulations, recruitment, and conflict, received similar levels of "major emphasis" across all four geographic divisions (Fig. 2a,b,c; Table 2c), again revealing national importance as evaluated by

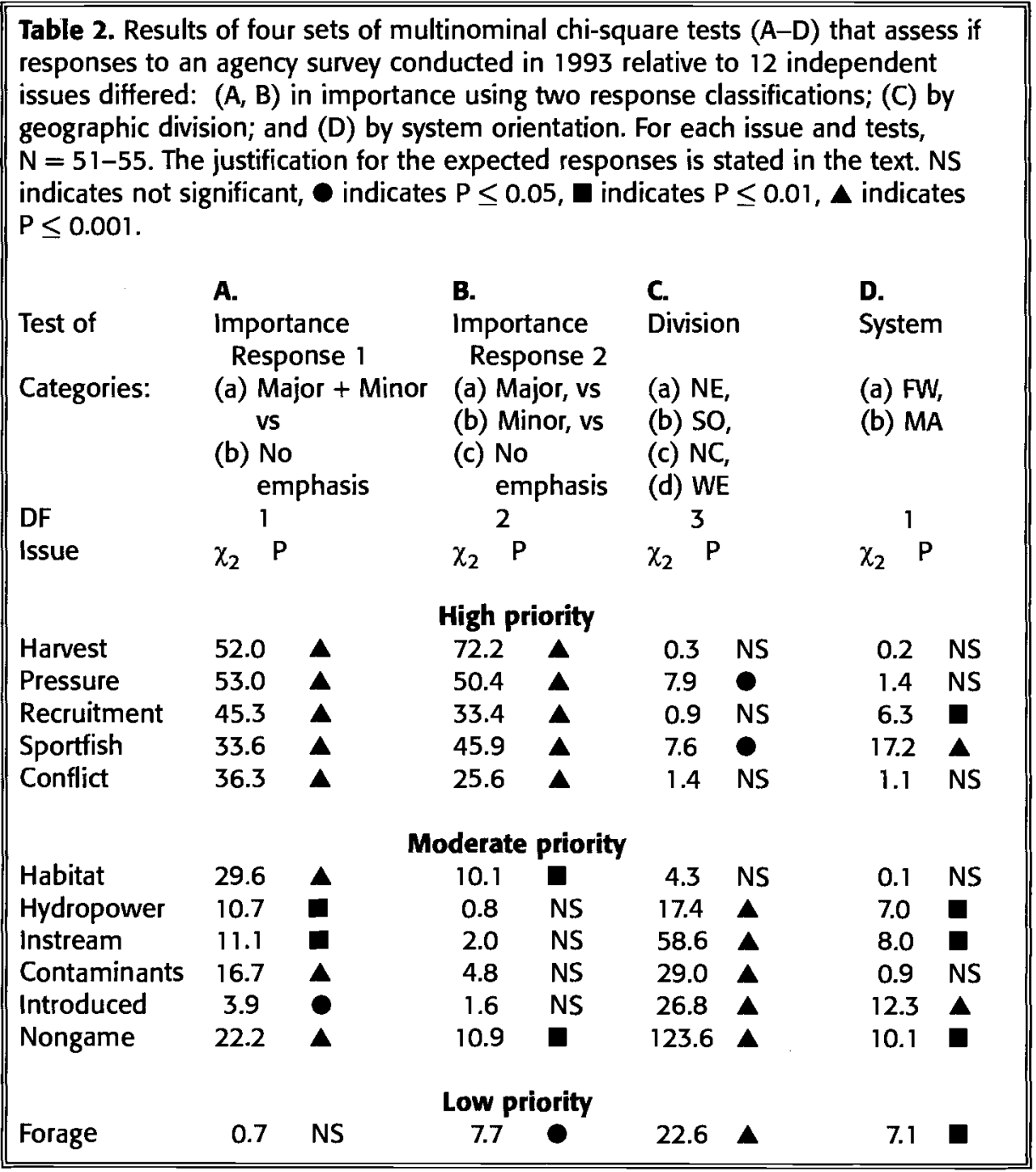


current agency personnel time allocation. Two other "high-priority" issues-fishing pressure and sportfish stocking-received more "majoremphasis" responses in the North
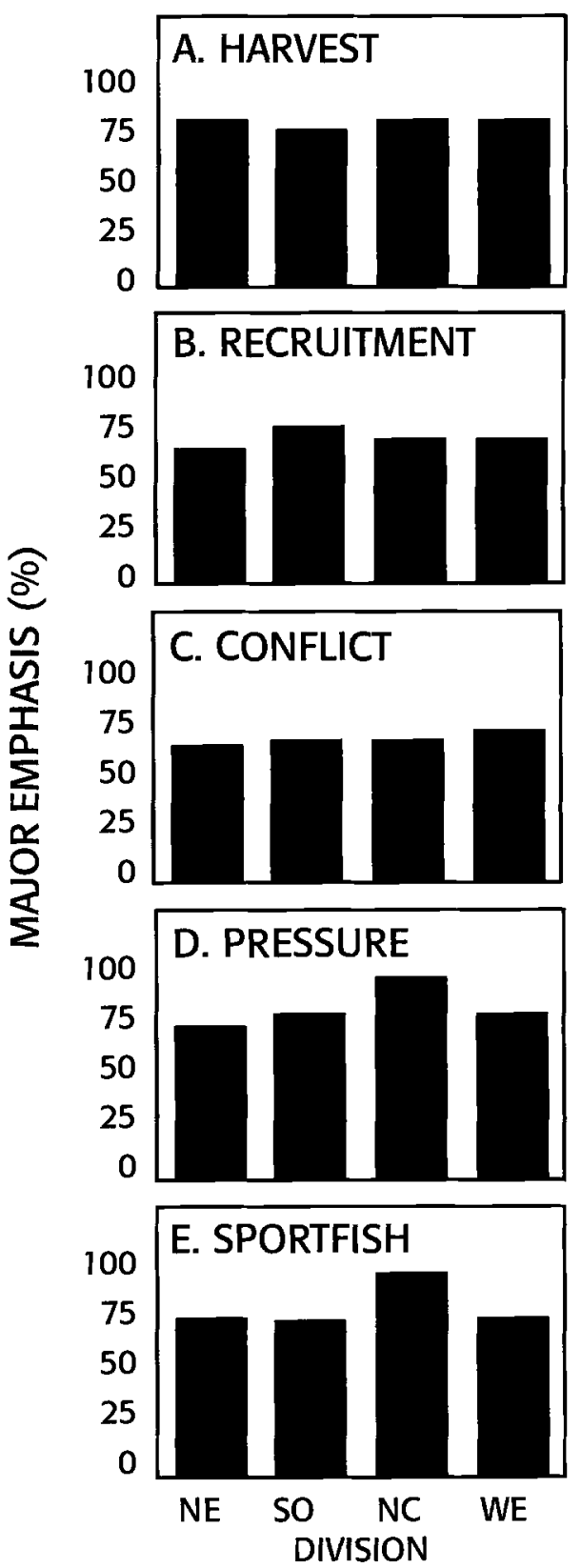

Fig. 2. Percentage of "major emphasis" for five fisheries management issues identified as "high priority" by respondents to a 1993 survey resid ing in four geographic divisions. Divisions correspond to those used by the AFS: NE, Northeastern Division; SO, Southern Division; NC, North Central Division; WE, Western Division. These five issues include (A) Applying or assessing the effectiveness of harvest regulations (HARVEST); (B) Recruitment (RECRUITMENT) (C) Conflict, policy, and human dimensions issues (CONFLICT); (D) Evaluation of fishing pressure (PRESSURE); and (E) Sportfish stocking (SPORTFISH). $\mathrm{N}=51-55$ for each issue.
Central Division (NC) in which $100 \%$ of the nine states responding rated these two issues as paramount (Fig. 2d, 2e; Table 2c).

Many issues ranked as "moderate priority" also exhibited intriguing geographic trends. Two issues, hydropower licensing and instream flow, received more emphasis in the Western Division (WE) and less emphasis in the Southern Division (SO) than in the Northeastern (NE) or North Central (NC) Divisions (Fig. 3a,b; Table $2 \mathrm{c}$ ). These results were not unexpected since water diversion and water shortages have long been issues in many arid areas of the West. These flow issues were important, based on agency personnel time allocation, in the Northeastern and North Central Divisions; however, our data revealed that southern states still allocate comparatively little time to flow concerns.

The issue titled nongame, threatened, or endangered species received substantially more emphasis in the West (Fig. 3c; Table 2c), perhaps because of the naturally depauperate western fish fauna, a history of water allocation problems, the importance of anadromous fish, public land use practices, and the prevalence of large hydropower projects. Another issue, habitat restoration, received similar emphasis from states in all geographic divisions (Fig. 3d; Table 2c).

Interestingly, states in the North Central Division allocated more time to introduced species than agencies in other regions (Fig. $3 e$; Table $2 \mathrm{c}$ ). This geographic pattern of emphasis for introduced species mirrors the geographic trend for sportfish stocking (Fig. 2e) and forage stocking (Table 2c). States in the southern and western parts of the North Central Division have many reservoirs, and when rivers are impounded to form these systems, native fish assemblages are often disturbed or destroyed. In turn, because reservoirs are often constructed for recreational fishing, intentional sportfish stocking becomes an important management tool with a resultant consequence of unintentional fish introductions into remaining stream reaches. Likewise, states in the northern part of the North Central Division emphasize sportfish stocking, although typically in natural lakes rather than artificial reservoirs. Although reservoirs are abundant in southern states, the presence in this region of marine agencies for whom stocking and introduced species are less of an issue may obscure any clear emphasis in the south.

In general, contaminants received greater emphasis in the Northeastern and North Central Divisions than in the Southern or Western Divisions (Fig. 3f; Table 2c). This geographic trend may be related to the high degree of urbanization in the Northeast, intensive farming in the Midwest with resultant high fertilizer and pesticide use, differential patterns of industrialization across the country, or variable legal structures relative to contaminant discharge across regions.

\section{Freshwater and Marine. System}

tion also affected how much personnel time an agency devoted to an issue. For five issues-harvest regulations, fishing pressure, conflict, habitat restoration, and contaminants-the percentage of "major emphasis" was similar for both inland and marine agencies (Fig. 4; Table 2d). However, for other issues, a slightly different pattern emerged. Specifically, recruitment was given a substantially higher level of "major emphasis" by marine agencies (Fig. 4). Conversely, five issues, i.e., sportfish stocking, hydropower, instream flow, nongame, and introduced species, were identified as receiving "major emphasis" almost twice as often by freshwater agencies (Fig. 4). Some issues-hydropower and instream flow-are clearly freshwater issues yet received major emphasis from a few marine agencies probably because of the inclusion of anadromous fish management in the marine administration structures of some states.

\section{Interpretation of Trends. $\begin{aligned} & \text { To } \\ & \text { sum- }\end{aligned}$} marize, issues directly linked to sportfishers and commercial fishers were of paramount importance in 
the time budgets of all state fisheries management agencies. Patterns of emphasis in the Northeast generally reflected that of the country as a whole with a slightly higher emphasis on contaminants and a reduced emphasis on nongame, threatened, and endangered species. Within the North Central Division, only freshwater interests exist. As a consequence, agency time largely was spent on sportfish management, including stocking, harvest evaluations, and fishing pressure assessments. Like the North Central Division, the states in the Southern Division contain a number of reservoirs in which sportfish are managed. However, because many southern states also have marine responsibilities that broaden their focus, clear patterns of emphases were diluted. Western states have regional concerns that include not only sportfishes but also flow and nongame and endangered species issues. Concerns relating to sport and commercial regulations, i.e., harvest and fishing pressure, were "high-priority" issues for both freshwater and marine agencies. However, because of the feasibility of stocking in freshwater systems and the difficulty of this management remedy in marine systems, freshwater agencies emphasize stocking, whereas marine agencies often allocate more time to exploring natural recruitment.

A majority of agencies identified conflict, policy, and human dimension issues as receiving "major emphasis" and indicated that the amount of time allocated to this issue was rapidly growing. Most fisheries biologists are trained as aquatic biologists and may not be equipped satisfactorily to deal with the social, cultural, economic, and policy aspects of their jobs. Though our survey reveals a need for understanding of the human dimensions of natural resource management by managers, it also supports the need for highly specialized biological and statistical expertise relating to a diverse array of fish biology issues (Parrish et al. 1995; R. A. Stein et al., unpublished). Thus, research, training, and education in
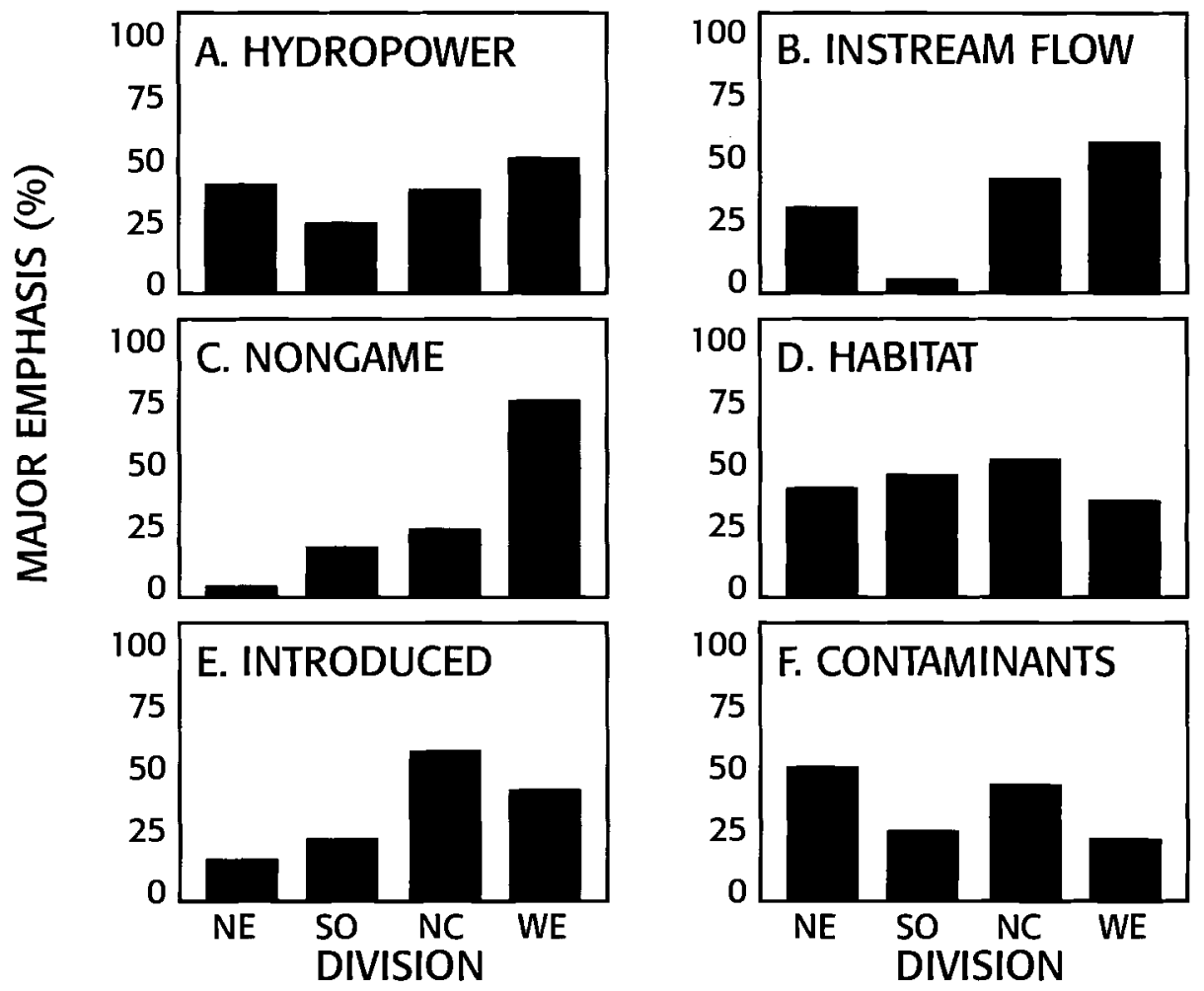

natural resource conflict, policy, and human dimensions are needed to complement, not supplant, biological training in fisheries. Only when Fig. 3. How the percentage of respondents that indicated a "major emphasis" changes with geographic division for six fisheries management issues classified as "moderate priority" based on a 1993 survey. Divisions correspond to those within the AFS: NE, Northeastern Division; SO, Southern Division; NC, North Central Division; WE, Western Division. Issues include (A) Hydropower licensing or regulated flow (HYDROPOWER); (B) Instream flow (INSTREAM); (C) Nongame, threatened, or endangered species (NONGAME); (D) Habitat restoration (HABITAT); (E) Introduced species (INTRODUCED); and (F) Contaminants (CONTAMINANTS). $\mathrm{N}=50-58$ for each issue.

expertise from

the biological and social science disciplines becomes integrated in a truly interdisciplinary fashion can we possibly hope to solve persistent fisheries allocation and management problems (Parrish et al. 1995; Stein et al., unpublished).

We also asked agencies to comment on their use of indices as a means to identify, report, and address management concerns. Many respondents commented that their personnel placed limited faith in the recommendations of indices. But surprisingly few agencies discounted the use of these sometimes-effective, sometimes-ineffective tools altogether. In their written comments, agency respondents recognized that many indices, however easy to use, were too simplistic to be meaningful because indices typically are unproven simplifications of complex problems. However, continued use of these potential tools by agencies, in spite of these reservations, suggests that if researchers developed relatively easy, accurate indices or tested the accuracy of existing indices, their findings would be welcomed by management agencies.

\section{Limitations Our objective of the Survey. in administer- ing this sur-}

vey was to collect information related to fisheries biology and management quickly and easily. As a consequence, some ambiguity existed in both questions and interpretations of responses. First, quantifying importance or priority is difficult, and a variety of criteria could be used. Clearly, (1) agency mission; (2) budget allocations; (3) agency employee attitudes, goals, and values; or (4) public satisfaction with agency activities might also determine agency 
MANOR EMPHASIS (\%)

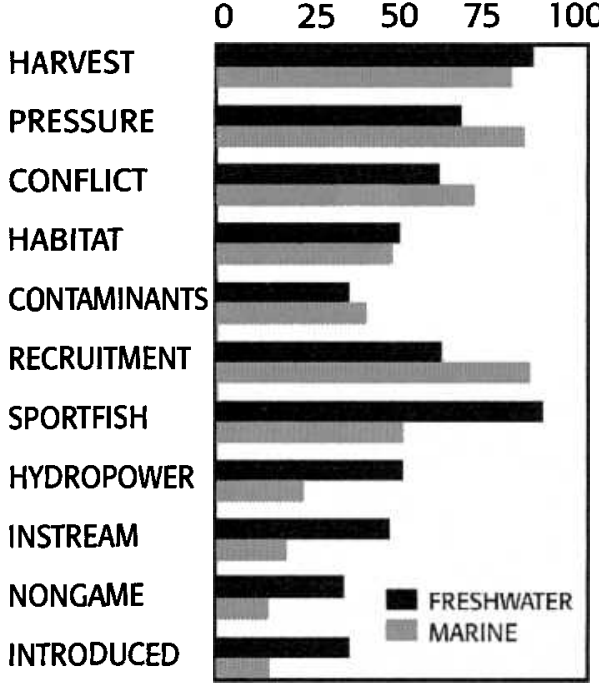

Fig. 4. Effect of marine and freshwater orientation on the degree of emphasis placed on fisheries management issues as reflected by a state agency time allocation survey conducted in 1993. Percent of agencies that indicated a "major emphasis" is shown for the following management issues: (1) Applying or assessing the effectiveness of harvest regulations (HARVEST); (2) evaluation of fishing pressure (PRESSURE); (3) conflict, policy, and human dimensions issues (CONFLICT); (4) habitat restoration (HABITAT); (5) contaminants (CONTAMINANTS); (6) recruitment (RECRUITMENT); (7) sportfish stocking (SPORTFISH); (8) hydropower licensing or regulated flow (HYDROPOWER); (9) instream flow (INSTREAM); (10) nongame, threatened, or endangered species (NONGAME); and (11) introduced species (INTRODUCED). $F W=37 ; \mathrm{MA}=15$.

priorities. In spite of these alternative criteria, we believe our approach using self-reported estimates of agency personnel time allocation reveals insightful information. In short, issues to which agencies allocate personnel time must, to some degree, be important or agencies are misallocating management time and agency dollars. However, because these other criteria by which management concerns can be prioritized represent valid alternatives, our results may not describe completely the relationship between management concerns and research needs.

Second, some respondents expressed confusion about how to quantify "major," "minor," and "no emphasis." Clearly, in the absence of detailed, highly prescribed definitions, this criterion can only be assessed subjectively, and some variability exists based on individual interpretation. Third, we asked agency personnel to assess current time allocation, i.e., what are agency staff doing now, not necessarily what should they be doing now or what will they be doing in the future. Many respondents argued that these "is versus will be" and "is versus should be" dichotomies were important distinctions. Thus, managers may believe strongly that certain issues are important but feel compelled to devote agency personnel to other issues for various reasons, i.e., political dictates, unexpected crises, budgetary constraints.

Fourth, management issues emphasized in our results may be strongly influenced by the traditional training that fisheries biologists receive. Consequently, by default, agencies may spend time on those issues with which fisheries biologists feel most comfortable or competent. For example, resource agencies have been poorly prepared to deal with social and economic research but can easily assess the response of fish populations to regulations. If management activities mirror traditional fisheries education rather than agency needs, our results may not reveal all of the management concerns and research needs important to agencies. Fifth, the structure of the data precludes higher-level statistical analyses and limits us to presenting descriptive results. Sixth, we did not separate sport and commercial interests clearly. In some states with separate marine agencies, commercial fishing license revenues and NOAA grant programs may contribute significantly to the agency's financial base. Of course, these sources of income will clearly influence agency priorities. Finally, many other research and management agencies, both federal (e.g., Fish and Wildlife Service, National Biological Service, National Marine Fisheries Service, Environmental Protection Agency, U.S. Forest Service) and state (e.g., departments of environmental protection and environmental management) are involved either directly or peripherally in managing and researching fish stocks, fish habitat, and fisheries user groups. Hence, the lack of emphasis by any agency may not necessarily represent a consciously prescribed priority but may instead reflect an organizational division of labor.

In spite of these points, we had a high response rate, most respondents completely filled out our questionnaire; most questionnaires could be easily classified as freshwater or marine; and many descriptive trends were obvious. Thus, we think we have presented a broad-brush, useful assessment of management issues that reflects contemporary fisheries management priorities as reflected by one important organizational measure, the amount of staff time purposefully devoted to specific fisheries issues. In summary, using this information, we now possess a better understanding of agency priorities by state, geographic region, and system orientation.

\section{Time Allocation, Agency Priorities, and Research Needs.}

Our study raised critical questions about the relationships between time spent on a management activity, the priority for that activity within an agency, and the need for research regarding that management activity. First, does more time spent on a specific management activity necessarily mean that the specified management activity is of greater concern to the agency? The activities on which an agency spends its time may not necessarily be the activities on which the agency should be spending its time. But we believe that in this time of fiscal austerity, expanding job responsibilities, shrinking personnel allocations, and increasing public scrutiny of government activities, time spent on specific management activities must reflect current agency priorities.

Second, does time spent on a management activity necessarily mean that more research is required in this area? It is conceivable that state management agencies are spending most of their time on activities about which they know much. If this is true, no need for further research on 
these activities exists. However, we believe that this is not typically the case and that a correlation exists between agency time allocated to an activity and the need for research, especially research that makes that management activity more accurate, useful, and cost-effective. On the other hand, management activities to which little time is currently allocated also may require attention by researchers. For example, management activities that are viewed either as too labor-intensive or too intractable for effective management, or are responses to newly emerging public concerns may not be allocated agency personnel time now even though they are important concerns. If this is true, germane research is needed that demonstrates an effective solution to these management concerns. With this information in hand, agency personnel time subsequently might be allocated to these previously ignored issues. Thus, research may be needed on management activities to which an agency allocates both much and little staff time. In summary, our survey has identified some, but certainly not all, areas where research and management can collaborate. Clearly, more clarification is needed on specific issues that are causing agency problems and more research is needed that helps agencies address these problems.

\section{Where Do We Go from Here?}

This survey provides one perspective on a nationwide ranking of fisheries management issues and how these priorities vary with geographic region and system orientation. As such, it provides a useful baseline for future longitudinal comparisons that may yield insights into the extent to which current issues subside and new issues emerge. In addition, our results may indicate the extent to which a program of research contributes to addressing management issues. Fisheries agencies may desire additional surveys that (a) provide further clarification of our findings, (b) compare and contrast different ways of evaluating priorities, or (c) reconcile current practices with future or desired time allocations. We hope that both common ground and important regional differences have been identified. Perhaps states or geographic regions that are facing problems new to their region can benefit from the management solutions of states that historically have

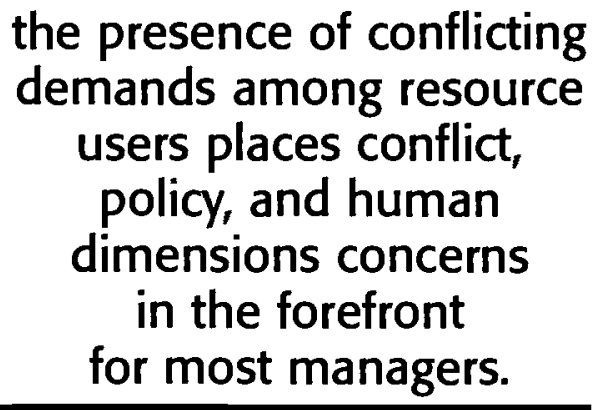

grappled with similar issues. As an example, flow issues, although long considered a western issue, are becoming an increasing focus for agencies in the Northeastern Division and to a lesser extent the North Central Division.

Many researchers are interested in addressing fisheries management problems because they believe that by helping to understand how things work, research can contribute to the solution of management problems (Stein et al., unpublished). To be effective, however, management and research need to communicate about research needs, management problems, and common goals (Parrish et al. 1995). Because persistent problems continue to plague agencies, these same agencies must clearly identify these management concerns for researchers. In our view, most importantly, this survey has identified areas of future collaboration between researchers and managers. The papers that follow address some of these issues, and each suggests new ways that research can address traditional concerns. For example, Johnson and Martinez (1995, this issue) address new ways to examine harvest regulations. We hope that the information presented in this paper and the papers that follow will help to initiate or strengthen effective researcher-manager dialogues.

\section{Acknowledgments}

We thank all of the state agencies that contributed to the survey. Marshall Adams, James Addis, Mark Bevelhimer, Dennis DeVries, Jeffrey Hard, Gary Isbell, Brett Johnson, Patrick Martinez, and Russell Wright contributed insightful presentations to the "Problem-solving Research for Management" symposium at the 1993 AFS meeting and stimulated much thought. University of Massachusetts paid for postage and mailing costs. Bernard Pientka provided technical assistance on figures and data analysis. Paul Cunningham, Ron Essig, Ken Fritz, Tom Savoy, and one anonymous reviewer provided helpful comments. The Massachusetts Cooperative Fish and Wildlife Research Unit is jointly sponsored by the National Biological Service, University of Massachusetts, Massachusetts Division of Marine Fisheries, Massachusetts Division of Fisheries and Wildlife, and Wildlife Management Institute. The Vermont Cooperative Fish and Wildlife Research Unit is jointly sponsored by the National Biological Service, University of Vermont, Vermont Department of Fish and Wildlife, and Wildlife Management Institute. The Massachusetts Cooperative Fish and Wildlife Research Unit (MEM), Vermont Cooperative Fish and Wildlife Research Unit (DLP), University of Massachusetts (RMM), The Ohio State University and Federal Aid in Fish Restoration Project F-69-P, and the Ohio Division of Wildlife (RAS) provided support during manuscript preparation.

\section{References}

Dowdy, S., and S. Wearden. 1991. Statistics for research. John Wiley and Sons, New York.

Johnson, B. M., and P. Martinez. 1995, this issue. Selecting harvest regulations for recreational fisheries: opportunities for research/management cooperation. Fisheries 20(10):22-30.

Parrish, D. L., M. E. Mather, and R. A. Stein. 1995, this issue. Problem-solving research for management: a perspective. Fisheries 20(10):6-12.

USFWS (U.S. Fish and Wildlife Service). 1991. Directory of national and state listing of fisheries offices. U.S. Fish and Wildlife Service, Washington, DC. 